( ) И.И. Дедов, М.В. Шестакова, В.А. Петеркова, О.К. Викулова, А.В. Железнякова, М.А. Исаков, Д.Н. Лаптев, Е.А. Андрианова, Т.Ю. Ширяева

ФГБУ Национальный медицинский исследовательский центр эндокринологии Минздрава России, Москва

ОБОСНОВАНИЕ. Данные регистра являются основным источником информации о пациентах с сахарным диабетом (СД) для повышения качества организации лечебной и профилактической помощи.

ЦЕЛЬ. Провести анализ эпидемиологических характеристик СД (распространенности, заболеваемости, смертности) у детей и подростков в РФ по данным Федерального регистра СД, оценить динамику данных параметров за период 2013-2016 гг., состояние углеводного обмена, структуру инсулинотерапии, частоту госпитализаций и частоту развития диабетических осложнений в данных возрастных группах.

МАТЕРИАЛЫ И МЕТОДЫ. Объектом исследования является база данных Федерального регистра СД - 81 региона РФ, включенного в систему онлайн-регистра.

РЕЗУЛЬТАТЫ. Общая численность пациентов с СД до 18 лет в РФ на 31.12.2016 г. составила 33081 человек, из них с СД 1 типа (СД1) - 95,9\% (31 727 чел.) и СД 2 типа (СД2) - 4,1\% (1354 чел.). Распространенность СД1 в $2013-2016$ гг. у детей составила 81,0-91,4/100 тыс. детского населения (д.н.), у подростков - 212,8-209,5/100 тыс. подросткового населения (п.н.). Заболеваемость СД1 у детей в 2016 г. составила 14,2/100 тыс. д.н., у подростков - 10,0/100 тыс. п.н. Распределение по уровню $\mathrm{HbA}_{1 с}$ у пациентов с СД1 в 2016 г: дети: <7,5\% - 32\%, 7,6-9,0\% - 33\%, >9\% - 35\%; подростки: <7,5\% - 25\%, 7,6-9,0\% - 30\%, >9\% - 45\%. Среди осложнений у детей и подростков наиболее часто регистрируется диабетическая нейропатия при СД1 в 10,9\% и 40,8\% случаев, при СД2 - в 4,7\% и 8,8\% соответственно, из сопутствующих заболеваний - артериальная гипертония и дислипидемия. Госпитализировались в анамнезе 43,8\% детей и 49,2\% подростков, большинство госпитализаций в 2016 г. (дети 71,9\%, подростки 67,1\%) было по причине СД.

ЗАКЛЮЧЕНИЕ. Установлено, что в динамике 2013-2016 гг. сохраняется рост распространенности СД1 у детей при относительно стабильных показателях у подростков. По данным регистра, в последние два года отмечено снижение темпов заболеваемости СД1 и, напротив, рост заболеваемости СД2 у детей. Установлены значительные межрегиональные различия в уровне заболеваемости и распространенности СД в регионах, расположенных в различных географических областях РФ. Частота диабетических осложнений у детей и подростков с СД варьирует. Установлена четкая связь частоты госпитализаций с выраженностью декомпенсации СД. В структуре терапии данной возрастной группы соотношение инсулинотерапии в шприцах-ручках и помповой терапии по данным регистра составляет 80,9\%/15,1\%.

КЛЮЧЕВЫЕ СЛОВА: сахарный диабет; эпидемиология; дети; подростки; распространенность; заболеваемость; смертность

\title{
DIABETES MELLITUS IN CHILDREN AND ADOLESCENTS ACCORDING TO THE FEDERAL DIABETES REGISTRY IN THE RUSSIAN FEDERATION: DYNAMICS OF MAJOR EPIDEMIOLOGICAL CHARACTERISTICS FOR 2013-2016
}

(c) Ivan I. Dedov, Marina V. Shestakova, Valentina A. Peterkova, Olga K. Vikulova, Anna V. Zheleznyakova, Mikhail A. Isakov, Dmitriy N. Laptev, Ekaterina A. Andrianova, Tatyana Y. Shiryaeva

Endocrinology Research Centre, Moscow, Russia

BACKGROUND: The data of the register is the main source of up-to-date information about patients with diabetes mellitus (DM). It's very important for improving the quality of medical care organization.

AIMS: to analyze the main epidemiological DM characteristics in Russian Federation (RF) (prevalence, incidence, mortality) in children and adolescents, to assess the dynamics of these parameters for the period 2013 - 2016, to analyze the status of compensation for carbohydrate metabolism, therapy of DM1, prevalence of diabetic complications and the reasons for hospitalizations in these age groups.

MATERIALS AND METHODS: The database of Federal DM registry of 81 regions was included in the online system.

RESULTS: The total number of patients under the age of 18 with DM in RF on 31.12.2016 was 33081 people, there were 95,9\% (31727 people) with DM1 and 4,1\% (1354 patients) with DM2. The prevalence of DM1 in 2013-2016 in children: 81.0 - 
91.4 / 100 ths., in adolescents - 212,8-209,5 / 100 ths. The DM1 incidence/100 thousand population in 2016 in children was $14,2 / 100$ ths., in adolescents $10,0 / 100$ ths. $\mathrm{HbA}_{1 \mathrm{c}}$ levels in $\mathrm{DM} 1$ was in children: $<7,5 \%$ in $32 \%, 7,6-9,0 \%$ in $33 \%,>9 \%$ in $35 \%$ of the patients; in adolescents $<7,5 \%$ in $25 \%, 7,6-9,0 \%$ in $30 \%,>9 \%$ in $45 \%$ of the patients. Among complications in children and adolescents with DM1, diabetic neuropathy is the most often recorded (in 10,9\% of cases and 40,8\%, respectively); among DM2 patients, diabetic neuropathy is registered in $4,7 \%$ and $8,8 \%$ in children and adolescents, respectively. There are associated diseases in DM2 patients - arterial hypertension and dyslipidemia. 43,8\% of children and 49,2\% of adolescents were hospitalized in the anamnesis, most hospitalizations in 2016 (children 71,9\%, adolescents 67,1\%) were due to diabetes.

CONCLUSIONS: It is established that in the dynamics of 2013-2016 the prevalence of DM1 in children continues to increase, with relatively stable indicators in adolescents. According to the register, during last two years there has been a decrease in the incidence of DM1 and, on the contrary, an increase in the prevalence/incidence of DM2 in children. Significant interregional differences in the level of incidence/prevalence have been established, especially in regions located in various geographic regions of the RF. The frequency of diabetic complications in children and adolescents with diabetes varies. There is an association of hospitalizations with higher $\mathrm{HbA} 1 \mathrm{c}$ level. In the structure of therapy of this age group the ratio of insulin therapy in syringes-pens and pump therapy is $80.9 \% / 15.1 \%$ according to the register.

KEYWORDS: diabetes mellitus; epidemiology; diabetes registry; prevalence, adolescents; incidence; mortality

Организация лечебной и профилактической помощи детям и подросткам с сахарным диабетом (СД) является приоритетным направлением в системе здравоохранения всех стран мира. СД - наиболее распространенное эндокринное и метаболическое нарушение у детей [1]. Так, по данным Международной федерации диабета - International Diabetes Federation (IDF), в 2000 г. в мире насчитывалось 395 тыс. детей с СД1. В 2017 г., по данным 8-го издания атласа IDF [2], общее количество пациентов с СД1 в возрасте до 20 лет возросло до 1 млн 106 тыс., из них - 586 тыс. детей (возраст <15 лет) при общей численности детского населения в мире 1,94 млрд. Ежегодно около 96100 детей заболевают СД1, при этом самые высокие показатели заболеваемости зафиксированы в США, Индии и Бразилии; Россия по данным IDF занимает 6-е место по количеству новых случаев СД1 у детей/ год (3100/год).

В Российской Федерации эпидемиологические исследования у детей и подростков начаты Эндокринологическим научным центром в 90-х гг. XX в. Первые данные о распространенности СД у детей в московской популяции опубликованы в 1999 г. [3]. В настоящее время основным источником эпидемиологических характеристик СД в различных возрастных группах является Федеральный (ранее Государственный) регистр больных СД.

ФГБУ «Национальный медицинский исследовательский центр эндокринологии» Минздрава России с 1996 г. является ключевым методологическим и организационным референс-центром Федерального регистра больных СД в РФ, основанного по Приказу Министерства здравоохранения РФ №404 от 10 декабря 1996 года в рамках реализации Федеральной Целевой Программы «Сахарный диабет» (тогда на бумажных носителях). С 2014 г. регистр СД трансформирован в единую электронную базу данных РФ с авторизированным онлайн доступом, включившую в 2017 г. большинство регионов РФ (81 регион РФ), что позволило повысить качество оценки распространенности СД и диабетических осложнений в в РФ [4].

В современном представлении регистр СД - это автоматизированная информационно-аналитическая система клинико-эпидемиологического мониторинга СД в масштабах всей страны, которая предусматривает наблюдение за пациентом от момента его включения в регистр на протяжении всего периода заболевания, регистрацию наличия и вида осложнений, показателей углеводного обмена и других лабораторных параметров, оценку структуры терапии в динамике, а также анализ структуры смертности.

\section{ЦЕЛЬ}

Провести анализ основных эпидемиологических характеристик СД у детей и подростков в РФ (распространенности, заболеваемости, смертности), состояния компенсации углеводного обмена по данным Федерального регистра СД, оценить динамику данных параметров за период 2013-2016 гг., а также провести анализ частоты диабетических осложнений, причин госпитализаций в данных возрастных группах, схем инсулинотерапии.

\section{МАТЕРИАЛЫ И МЕТОДЫ}

Объектом исследования является база данных Федерального регистра СД - 81 регион РФ, включенный в систему онлайн-регистра.

Общая численность детей и подростков с СД в РФ указана по данным на 31.12.2016г. (79 регионов - из онлайн регистра и 6 регионов, не работавших онлайн в 2016 г. - по данным Федеральной службы государственной статистики (Росстат)) [5]. Показатели распространенности, заболеваемости и смертности представлены для 81-го региона РФ, вошедших в онлайн регистр в 2017г. [6].

Для расчета показателей распространенности, заболеваемости и смертности на 100 тыс. детского (д.н.) и подросткового населения (п.н.) использованы сведения о численности населения в регионах РФ по данным Федеральной службы государственной статистики (Росстат) [6].

Распространенность - показатель, оценивающий количество всех случаев заболевания, зарегистрированных в текущем календарном году, рассчитывается на 100 тыс. населения соответствующей возрастной группы.

Заболеваемость (первичная, по обращаемости) показатель, оценивающий количество новых случаев заболевания, впервые зарегистрированных в текущем календарном году, рассчитывается на 100 тыс. населения соответствующей возрастной группы. 
Таблица 1. Показатели распространенности СД у детей и подростков/100 тыс. населения на 31.12.2016 (81 регион РФ по данным онлайн-регистра)

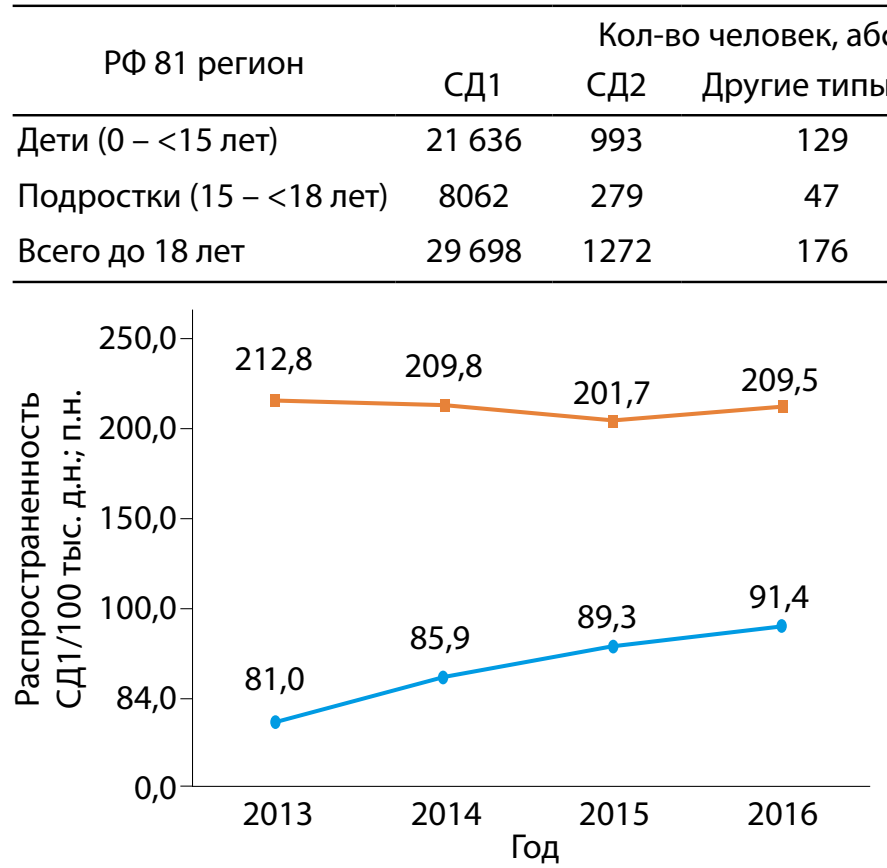

$\rightarrow-$ СД1 дети $(0-<15$ лет) $-=$-СД1 подростки $(15-<18$ лет)

Рис. 1. Динамика распространенности СД1 у детей и подростков/100 тыс. населения, 2013-2016 гг., 81 регион РФ.

Смертность - показатель, оценивающий количество смертей у лиц с данным заболеванием, рассчитывается на 100 тыс. населения соответствующей возрастной группы.

Дети - лица в возрасте до 15 лет (0 - <15 лет).

Подростки - лица в возрасте от 15 до 18 лет (15 - <18 лет).

\section{РЕЗУЛЬТАТЫ}

Анализ распространенности СД у детей и подростков в Российской Федерации

Общая численность детей и подростков с СД на 31.12.2016 г. в РФ составила 33081 человек, из них с СД1 - 95,9\% (31 727 чел.) и СД2 - 4,1\% (1354 чел.) [5].

Показатели распространенности СД/100 тыс. населения по данным онлайн-регистра в 81 регионе РФ представлены в табл. 1. Данные по каждому из 81 региона представлены в Приложении 1.

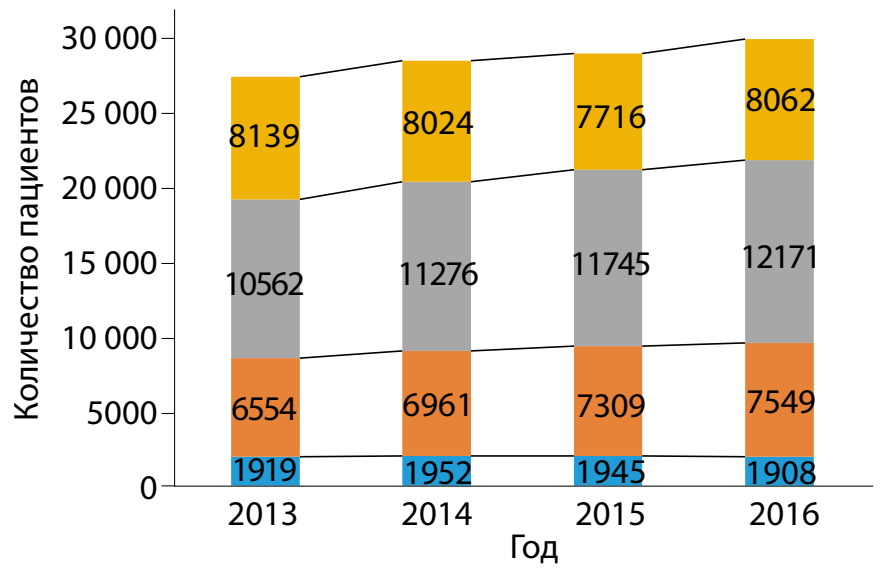

- 0 - <5 года $\square-<10$ лет $10-<15$ лет $15-<18$ лет

Рис. 2. Динамика количества пациентов с СД1 до 18 лет по возрастным группам, 2013-2016 гг., 81 регион РФ.
На 100 тыс. населения

СД2 Другие типы СД Всего

$22758 \quad 91,4 \quad 4,2 \quad 0,5 \quad 96,1$

$8388 \quad 209,5 \quad 7,2 \quad 1,2$

217,9

$31146 \quad 107,9 \quad 4,6 \quad 0,6$

113,1

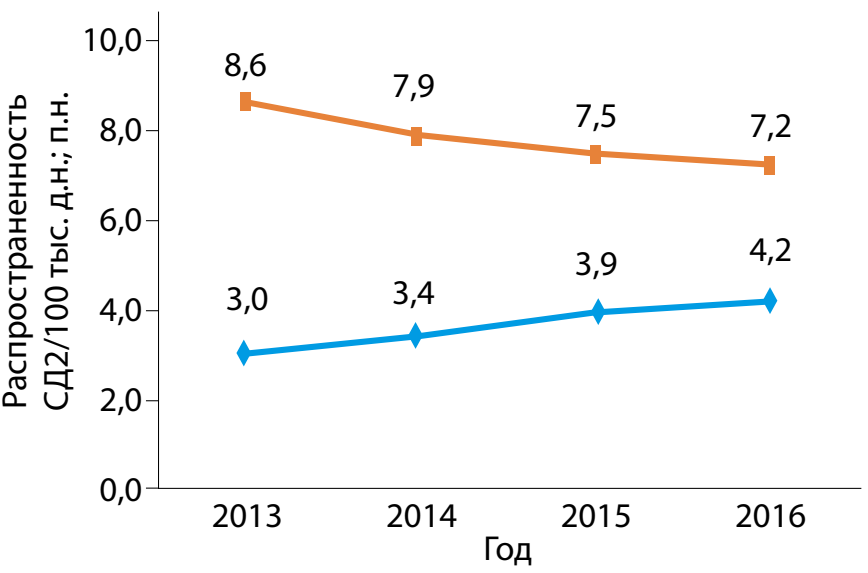

$\rightarrow$ СД1 дети $(0-<15$ лет) -- СД1 подростки $(15-<18$ лет)

Рис. 3. Динамика распространенности СД2 у детей и подростков/100 тыс. населения, 2013-2016 гг., 81 регион РФ.

СД1: динамика распространенности СД1/100 тыс. населения указывает на преимущественный рост данного показателя среди детей - с 81,0 до 91,4/100 тыс. д.н. в 2013-2016 гг. при относительно стабильной распространенности СД1 у подростков - 212,8 против 209,5/100 тыс. п.н. соответственно (рис. 1). Распределение групп по возрасту отражает стабильный рост количества пациентов с СД1 среди лиц до 18 лет во всех возрастных группах: 5 - <10 лет, 10 - <15 лет и 15 - <18 лет, за исключением группы 0 - <5 года, где регистрировалось стабильное количество пациентов в течение 4 лет (рис. 2).

По данным на 01.01.2012 г., где суммарно анализировались анкетные сведения из регионов и данные Государственного регистра СД, распространенность СД1 у детей на 01.01.2012 г. составляла 72,8/100 тыс. д.н. [7]. Таким образом, на 31.12.2016 г. следует констатировать рост распространенности СД1 у детей по сравнению с 2012 г. в 1,25 раза - 91,4/100 тыс. д.н. При более раннем

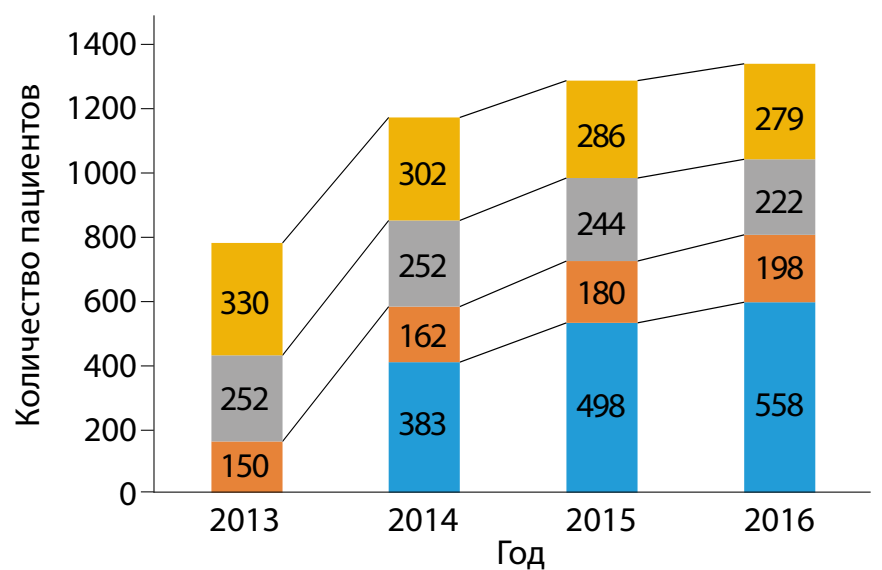

घ 0 - $<5$ года $\square 5-<10$ лет $10-<15$ лет $\square 15-<18$ лет

Рис. 4. Динамика количества пациентов с СД2 до 18 лет по возрастным группам, 2013-2016 гг., 81 регион РФ. 


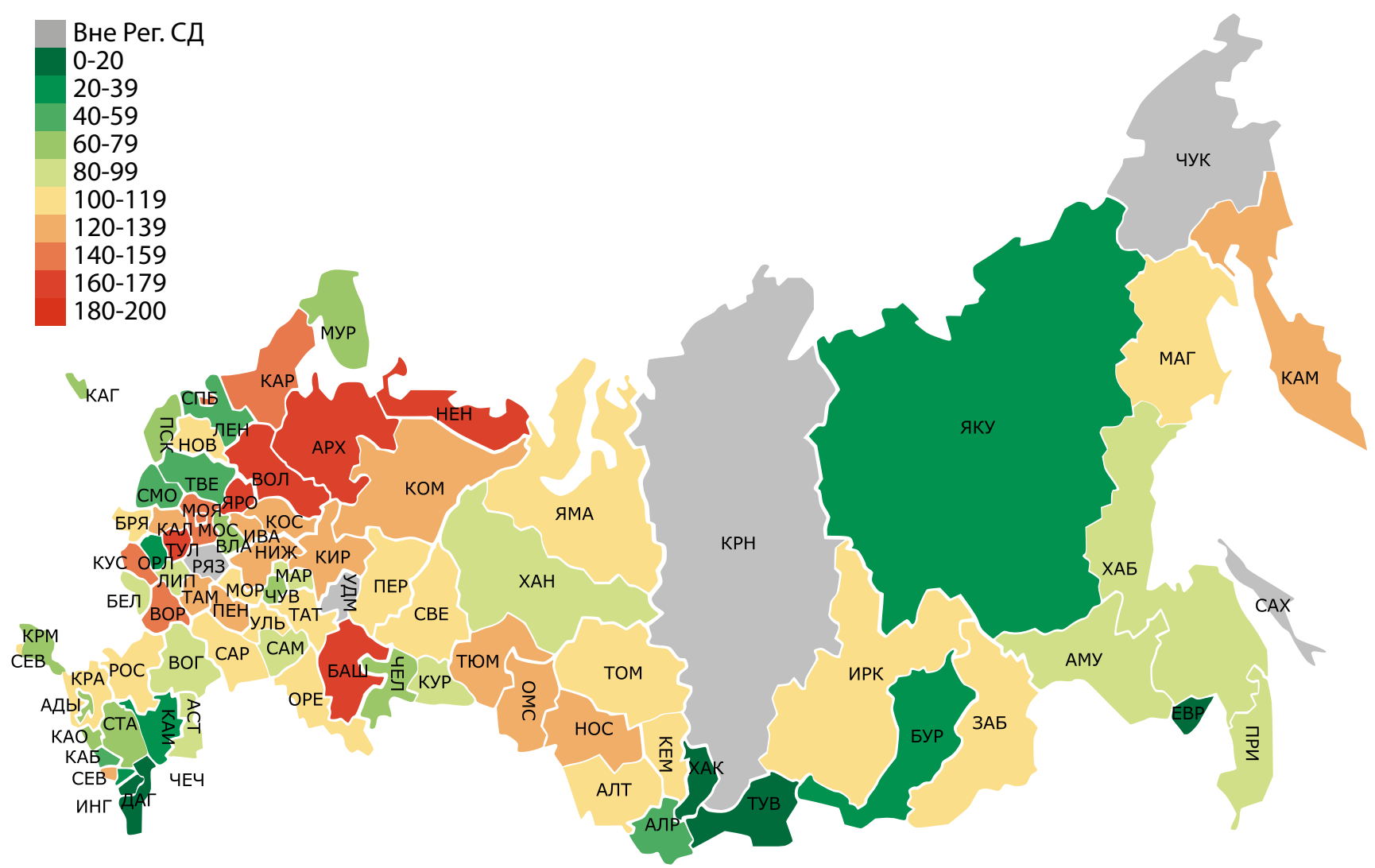

Рис. 5. Градиент распространенности СД1/100 тыс. населения у лиц до 18 лет (дети и подростки).

Таблица 2. Анализ распространенности СД в зависимости от места жительства у лиц до 18 лет.

\begin{tabular}{lcccc}
\hline \multirow{2}{*}{ Населенный пункт } & \multicolumn{2}{c}{ СД1 } & \multicolumn{2}{c}{ СД2 } \\
& 2015 & 2016 & 2015 & 2016 \\
\hline Город, n (\%) & 20440 & 21054 & 656 & 635 \\
& $(71,4)$ & $(71,0)$ & $(55,1)$ & $(52,0)$ \\
Село/деревня, n (\%) & 6208 & 6417 & 384 & 405 \\
& $(21,7)$ & $(21,7)$ & $(32,3)$ & $(33,1)$ \\
Нет данных, n (\%) & 1984 & 2165 & 150 & 182 \\
& $(6,9)$ & $(7,3)$ & $(12,6)$ & $(14,9)$ \\
\hline
\end{tabular}

анализе распространенности СД1 у детей в РФ за 10-летний период (2000-2009 гг.) уровень распространенности возрастал с 59,4 до 80,6/100 тыс. д.н. [8].

Аналогичные тенденции прослеживаются в группе подростков: распространенность по данным на 01.01.2012 г. составляла 92,6/100 тыс. п.н. [7], таким образом, в 2016 г. данный показатель вырос в 2,26 раза и составил 209,5/100 тыс. п.н. В анализе распространенности СД1 уподростков в РФ (2000-2009гг.) уровень распространенности возрастал со 108,5 до 183,5/100 тыс. п.н. [8]. Данные СД2 у детей и подростков ранее не анализировались.
СД2: динамика распространенности СД /100 тыс. д.н. также указывает на преимущественный рост данного показателя среди детей - с3,0 до 4,2/100 тыс.д.н. в 2013-16гг. (рис. 3). В группе подростков наблюдается некоторое снижение распространенности СД2 с 8,6/100 тыс. п.н. в 2013 г. до 7,2/100 тыс. п.н. в 2016 г. Динамика количества пациентов с СД2 у лиц до 18 лет по возрастным группам 0 - <5 года, 5 - <10 лет, $10-<15$ лет, $15-<18$ лет подтверждает общие тенденции (рис. 4) [2], при этом наиболее выражен рост количества детей с СД2 в младшей возрастной группе от 0 до 4 лет, что может отражать более раннюю диагностику СД2 у детей.

Таким образом, дети в возрасте $10-<15$ лет представляют собой когорту наиболее высокого риска, где наблюдается не только рост распространенности СД1, патогномоничного для данной возрастной группы, но и увеличение распространенности СД2. Эта опасная тенденция может являться следствием высокой распространенности избыточного веса и ожирения не только у взрослых, но и в детской группе пациентов. Существующие мировые данные подтверждают аналогичные тренды в других странах мира [2]. С учетом ожидаемой длительности СД при дебюте в детском возрасте риск развития хронических диабетических осложнений возрастает, что имеет все шансы стать серьезной пробле-

Таблица 3. Показатели заболеваемости СД у детей и подростков/100 тыс. населения на 31.12.2016 (81 регион РФ по данным онлайн-регистра)

\begin{tabular}{lcccccccc}
\hline \multicolumn{1}{c}{ РФ 81 регион } & \multicolumn{4}{c}{ Кол-во человек } & \multicolumn{5}{c}{ На 100 тыс. населения } \\
& СД1 & СД2 & Другие типы СД & Всего & СД1 & СД2 & Другие типы СД & Всего \\
\hline Дети (0-<15 лет) & 3352 & 228 & 26 & 3606 & 14,2 & 1,0 & 0,1 & 15,3 \\
Подростки (15-<18 лет) & 384 & 44 & 6 & 434 & 10,0 & 1,1 & 0,2 & 11,3 \\
Всего до 18 лет & 3736 & 272 & 32 & 4040 & 13,6 & 1,0 & 0,1 & 14,7 \\
\hline
\end{tabular}




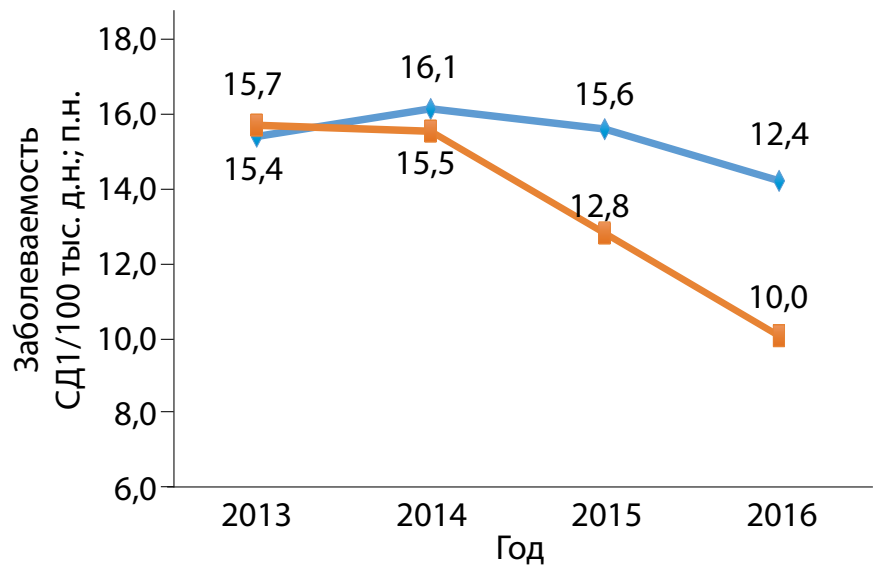

$\rightarrow$ СД1 дети $(0-<15$ лет) --СД1 подростки $(15-<18$ лет)

Рис. 6. Динамика заболеваемости СД1 детей и подростков/100 тыс. населения, 2013-2016 гг., 81 регион РФ.

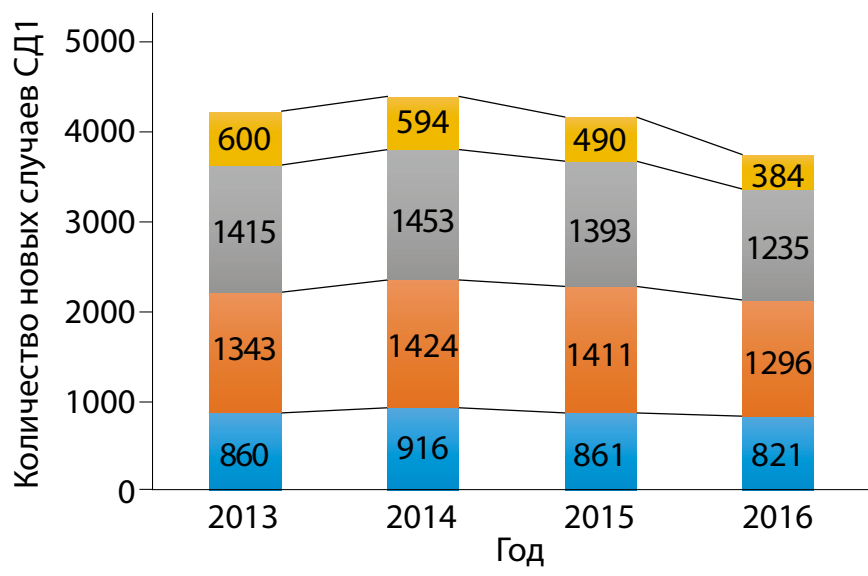

ш 0 - <5 года $\square 5-<10$ лет $10-<15$ лет $15-<18$ лет

Рис. 7. Динамика количества новых случаев СД1 в год у лиц до 18 лет по возрастным группам, 2013-2016 гг., 81 регион РФ.

мой здравоохранения, связанной с тяжелыми последствиями для здоровья пациентов и социального ущерба для общества в целом. Этот аспект эпидемии СД у детей требует наиболее пристального внимания органов здравоохранения.

Данные распространенности СД1/100 тыс. населения у лиц до 18 лет указывают на значительные географические различия показателя (рис. 5) - классический градиент «север-юг» и «запад-восток», с наибольшей распространенностью СД1 в северо-западных регионах РФ $[3,7,9,10]$.

Среди анализа факторов, влияющих на эпидемиологическую ситуацию СД, большое внимание уделяется процессам урбанизации, влиянию факторов загрязнения окружающей среды на развитие и течение заболевания и его осложнений [7]. По данным Федерального регистра регистрируются достоверно более высокие показатели распространенности СД среди детского населения городов (табл. 2).

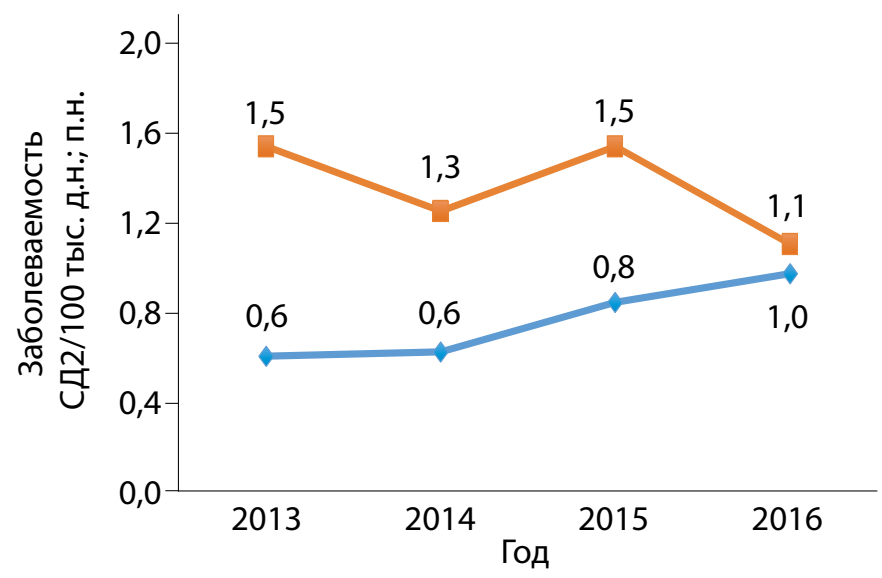

- СД1 дети (0 - <15 лет) - - СД1 подростки (15 - <18 лет)

Рис. 8. Динамика заболеваемости СД2 у детей и подростков/100 тыс. населения, 2013-2016 гг., 81 регион РФ.

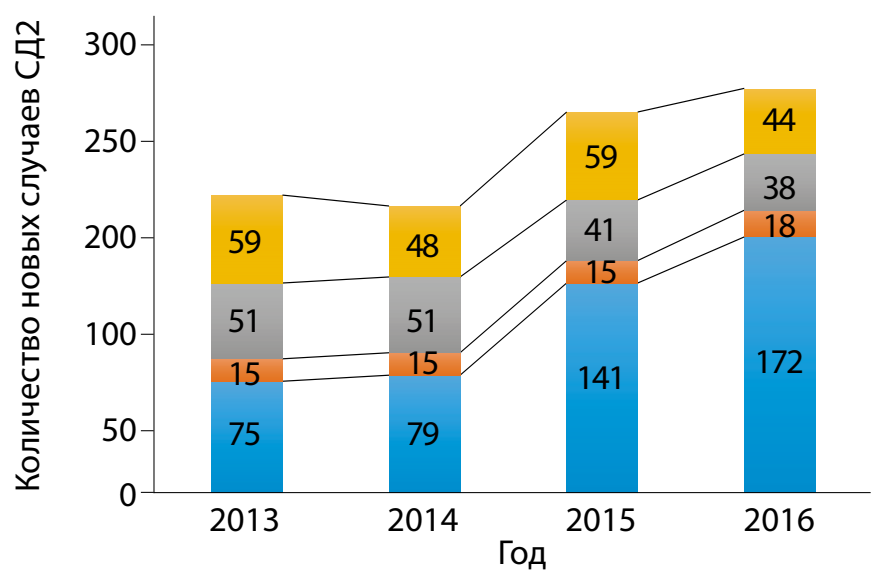

घ 0 - <5 года $\square 5-<10$ лет $10-<15$ лет $\square 15-<18$ лет

Рис. 9. Динамика количества новых случаев СД2 в год у лиц до 18 лет по возрастным группам, 2013-2016 гг., 81 регион РФ.

Анализ заболеваемости сахарным диабетом

в Российской Федерации

Показатели заболеваемости СД/100 тыс. населения, по данным онлайн-регистра, в 81 регионе РФ на 2016 г. представлены в табл 3. Данные по каждому из 81 региона - в Приложении 2.

СД1: динамика заболеваемости СД1 у детей на 100 тыс. д.н. указывает на пик показателя в 2014 г. со значением $16,1 / 100$ тыс. и далее снижение до 14,2/100 тыс. д.н. в 2016 г., у подростков отмечено снижение с 15,7/100 тыс. п.н. в 2013 г. до 10,0/100 тыс. п.н. в 2016 г. (рис. 6). По данным на 01.01.2012 г., где суммарно анализировались анкетные сведения из регионов и данные Государственного регистра СД, за 11-летний период наблюдения с 2001 г. по 2011 г. отмечался ежегодный прирост заболеваемости в среднем - 2,82\% в год с показателем 12,4/100 тыс. д.н. и 15,3/100 тыс. п.н. в 2011 г. [7]. По нашим данным, на 31.12.2016 г. заболеваемость СД1 у детей составила 14,2/100 тыс. д.н., что по сравнению

Таблица 4. Показатели смертности при СД у детей и подростков/100 тыс. населения на 31.12 .2016 (81 регион РФ по данным онлайн-регистра)

\begin{tabular}{|c|c|c|c|c|c|c|}
\hline \multirow{2}{*}{ РФ 81 регион } & \multicolumn{3}{|c|}{ Кол-во человек } & \multicolumn{3}{|c|}{ На 100 тыс. населения } \\
\hline & СД1 & СД2 & Всего & СД1 & СД2 & Всего \\
\hline Дети (0 - <15 лет) & 12 & 9 & 21 & 0,05 & 0,04 & 0,089 \\
\hline Подростки (15 - <18 лет) & 4 & 1 & 5 & 0,10 & 0,03 & 0,13 \\
\hline Всего до 18 лет & 16 & 10 & 26 & 0,06 & 0,04 & 0,095 \\
\hline
\end{tabular}




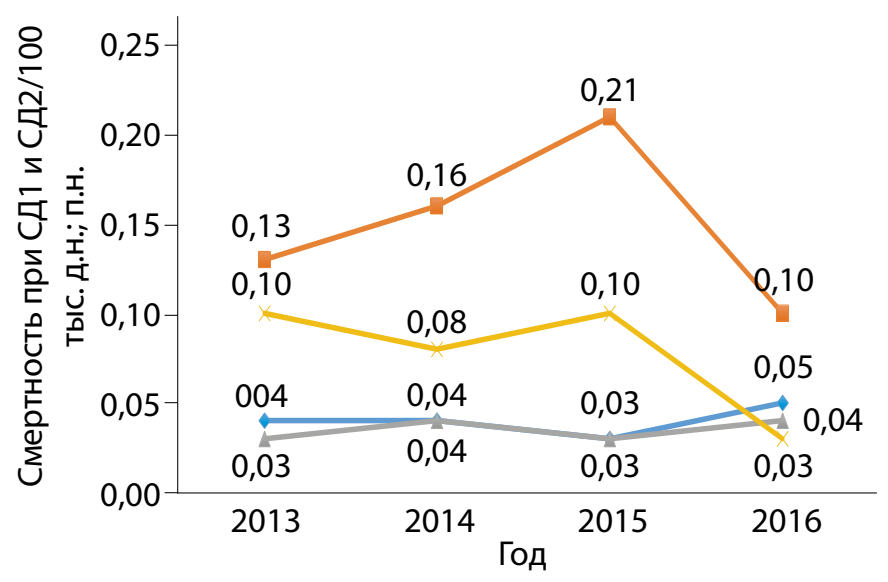

$\rightarrow$ Дети СД1 (0 - <15 лет) - -Подростки СД1 (15 - <18 лет) - Дети СД2 (0 - <15 лет) - Подростки СД2 (15 - <18 лет)

Рис. 10. Динамика смертности у детей и подростков с СД

1 и 2 типа /100 тыс. населения, 2013-2016 гг., 81 регион РФ.

с 2011 г. выше в 1,14 раза, у подростков 10,0/100 тыс. п.н., что в 1,5 ниже по сравнению с 2011 г. соответственно. Таким образом, в отличие от стабильного роста распространенности СД1, следует констатировать относительную стабилизацию темпов роста заболеваемости СД1 как у детей, так и у подростков.

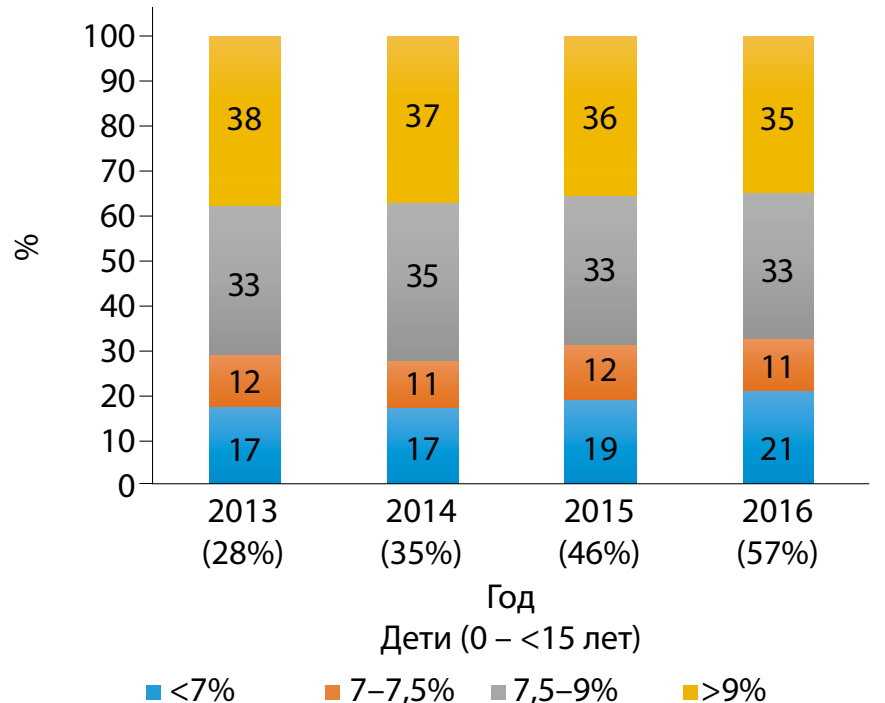

Распределение количества пациентов по возрасту отражает относительное снижение заболеваемости СД1 у лиц до 18 лет в последние 2 года во всех возрастных группах: 0-4 года, 5-9 лет, 10-14 лет, 15-18 лет (рис. 7).

СД2: динамика заболеваемости СД2/100 тыс. населения также указывает на преимущественный рост данного показателя среди детей - с 0,6 до 1,0/100 тыс. д.н. в 2013-2016 гг. (рис. 8). В группе подростков наблюдается относительное снижение заболеваемости СД2: от 1,5 до 1,1/100 тыс. п.н. По возрастным группам $0-<5$ года, 5 - <10 лет, 10 - <15 лет, 15 - <18 лет (рис. 9) наиболее выражен рост количества детей с СД2 в младшей возрастной группе от 0 до 4 лет.

Установлены значительные различия в уровне заболеваемости и распространенности СД между регионами, что может отражать не только этнические и географические особенности. На показатели в значительной степени оказывает влияние качество ведения регистра. Отсутствие внимания к регулярности обновления базы данных регистра может быть основным фактором искусственного занижения показателей заболеваемости СД в ряде регионов.

Мировые тенденции демонстрируют рост заболеваемости СД1 среди детей, средние темпы годового

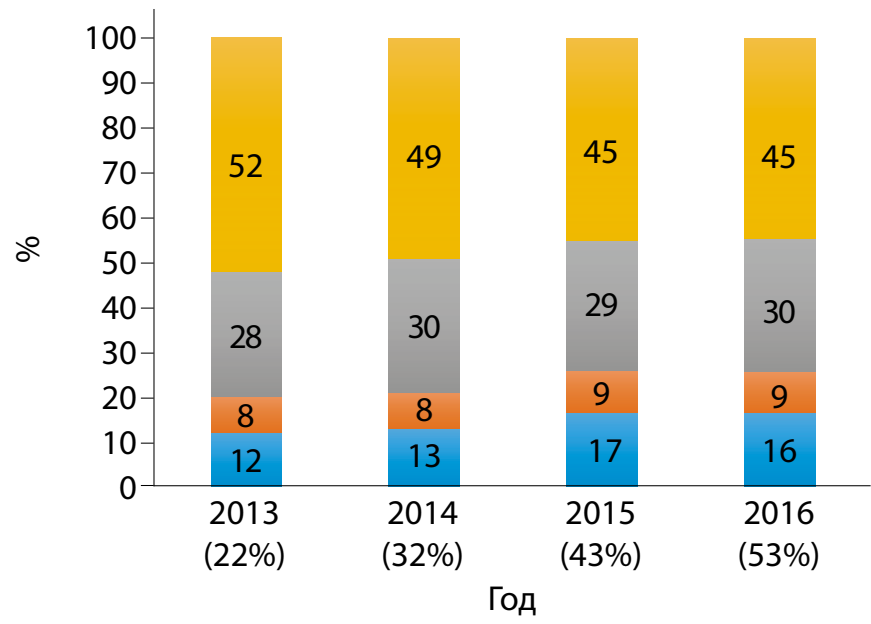

Подростки (15 - <18 лет)

$$
\text { - }<7 \% \quad \square-7,5 \% \quad \square, 5-9 \% \quad \square 9 \%
$$

Рис. 11. Динамика $\mathrm{HbA}_{1 с}$ у детей и подростков с СД1, 2013-2016 гг. (81 регион РФ по данным онлайн-регистра).

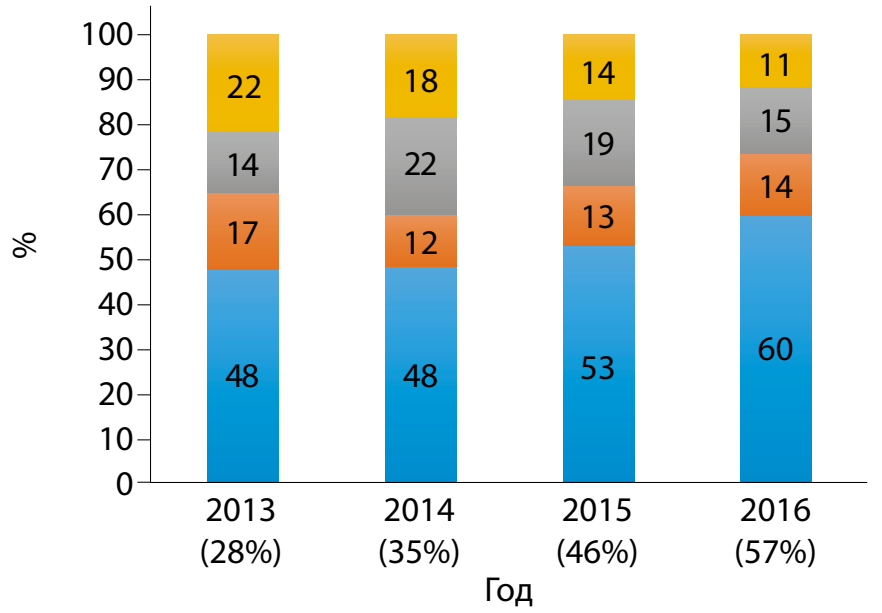

Дети $(0-<15$ лет)

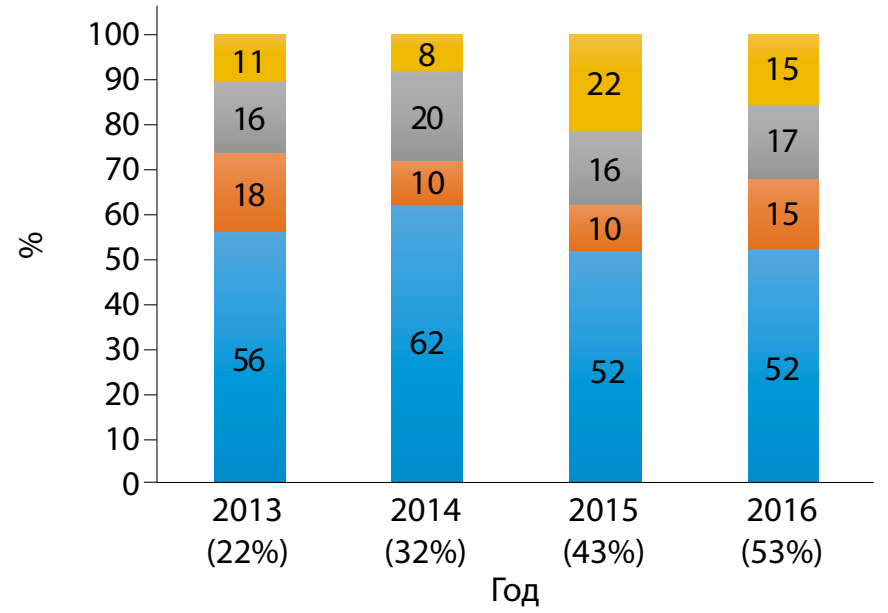

Подростки (15 - <18 лет)

$$
\text { घ }<\text { 7\% } \quad-7-7,5 \% \quad \square, 5-9 \% \quad \square 9 \%
$$

$\square-7,5 \% \quad \square, 5-9 \% \quad \square 9 \%$

Рис. 12. Динамика $\mathrm{HbA}_{1 с}$ у детей и подростков с СД2, 2013-2016 гг. (81 регион РФ по данным онлайн-регистра). 
Дети (0 - <15 лет) СД 1 типа

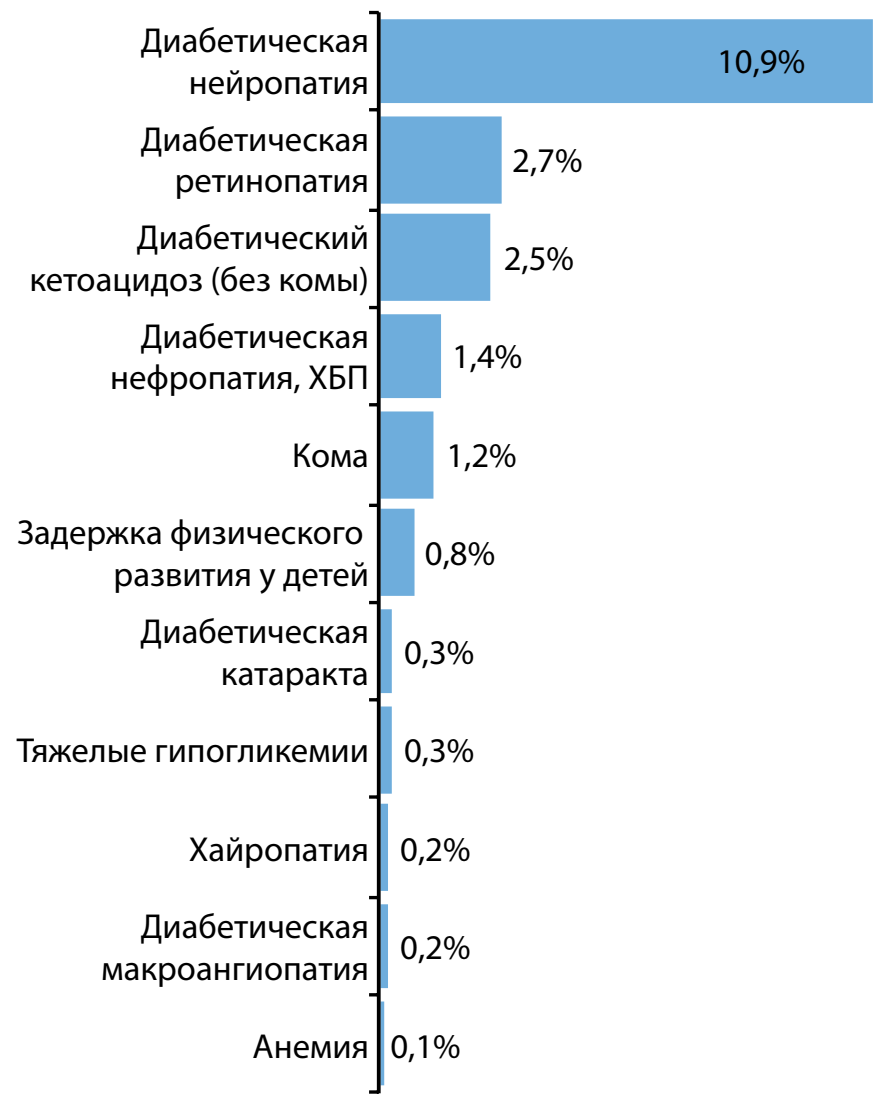

Подростки (15-<18 лет) СД 1 типа

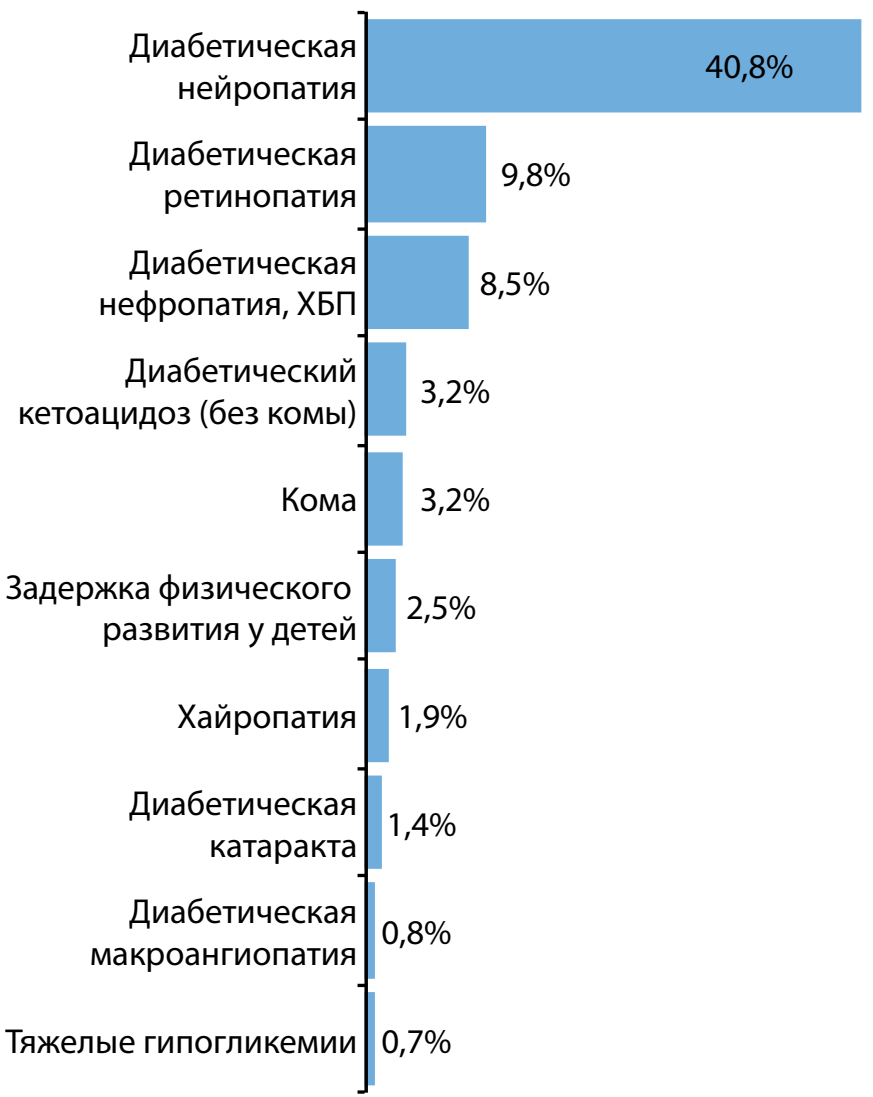

Рис. 13. Частота осложнений при СД1 у детей (N=20 234 человека) и подростков (N=8271 человек), 81 регион $\mathrm{PФ,} 2016$ г.
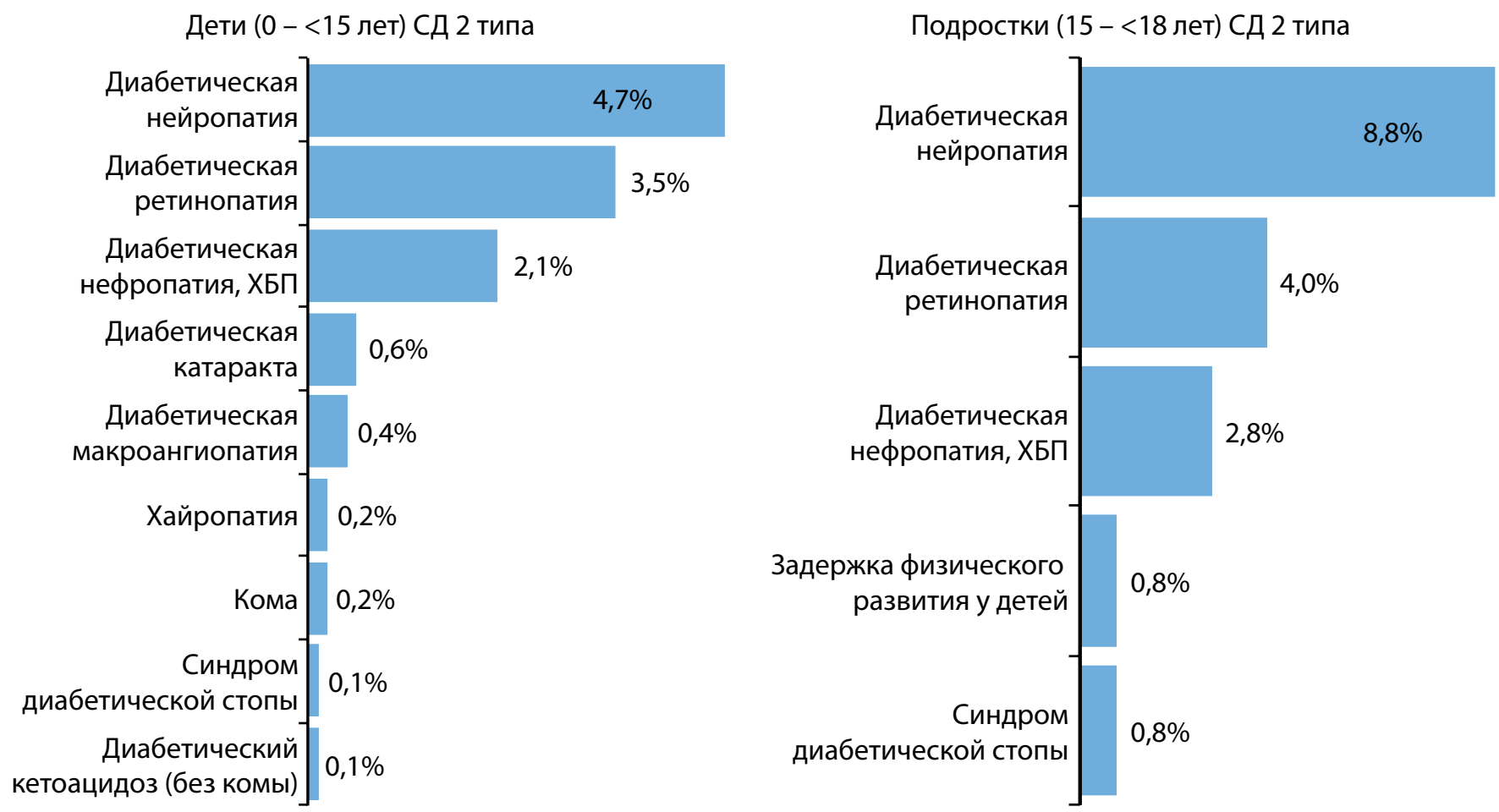

Рис. 14. Частота осложнений при СД2 у детей (N=894 человека) и подростков ( $\mathrm{N}=249$ человек), 81 регион $\mathrm{PФ}, 2016$ г.

прироста составляют 3\% [2]. Прослеживаются значительные географические различия: более выраженный рост заболеваемости СД1 отмечается в некоторых странах Центральной и Восточной Европы. Кроме того, ряд европейских исследований указывает, что в относительном выражении этот прирост наиболее выражен среди детей младшего возраста [11].

\section{Анализ смертности у больных сахарным диабетом} в Российской Федерации.

Показатели смертности при СД у детей и подростков представлены по данным онлайн-регистра в 81 регионе РФ (табл. 4).

Показатели смертности во всех возрастных группах детей и подростков находятся на стабильно низком уровне от 0,03/100 тыс. д.н. до 0,21/100 тыс. 
Таблица 5. Количество госпитализаций у пациентов с СД детского и подросткового возраста (81 регион РФ по данным онлайн-регистра)

\begin{tabular}{|c|c|c|c|c|c|c|}
\hline \multirow{2}{*}{ Группа } & \multicolumn{2}{|c|}{$\begin{array}{c}\text { Госпитализации в анамнезе } \\
\text { (по любой причине) }\end{array}$} & \multicolumn{2}{|c|}{$\begin{array}{c}\text { Госпитализации в } 2016 \text { г. } \\
\text { (по любой причине) }\end{array}$} & \multicolumn{2}{|c|}{$\begin{array}{c}\text { Госпитализации в } 2016 \text { г. } \\
\text { (по причине СД) }\end{array}$} \\
\hline & Абс. & $\%$ & Абс. & $\%$ & Абс. & $\%$ \\
\hline Дети (0 - <15 лет) & 9257 & 43,8 & 6209 & 61,7 & 4466 & 71,9 \\
\hline Подростки (15 - <18 лет) & 4194 & 49,2 & 2526 & 60,2 & 1696 & 67,1 \\
\hline
\end{tabular}

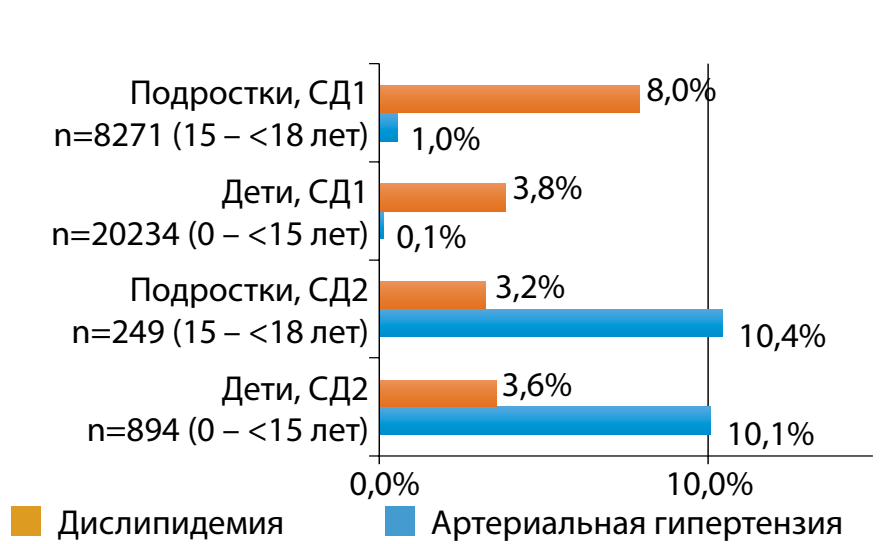

Рис. 15. Частота сопутствующих заболеваний при СД у детей и подростков, 81 регион РФ, 2016 г.

п.н. (рис. 10). Данные о причинах смерти в период 2013-2016 гг. представлены в Приложении 3. К сожалению, среди наиболее частых причин смерти указывается «причина смерти не установлена», т.е. не классифицируемые данные.

По данным на 01.01.2012 г., где суммарно анализировались анкетные сведения из регионов и данные Государственного регистра СД, смертность детей с СД1 в среднем составляла 0,07/100 тыс. д.н. (от 0 до 0,26 в различных регионах) [7]. Таким образом, роста показателя смертности за 5-летний период не отмечено.

\section{Анализ состояния компенсации углеводного обмена} (уровня $\mathrm{HbA}_{1 \mathrm{c}}$ )

Распределение детей и подростков по уровню гликированного гемоглобина $\mathrm{A}_{1 c}\left(\mathrm{HbA}_{1 c}\right)$ в динамике в 2013-2016 гг. представлено на рис. 11 и 12.

Учитывая допустимый целевой уровень $\mathrm{HbA}_{1 c}$ для детей и подростков <7,5\% [12], можно отметить неудовлетворительные показатели данного параметра с достижением целевого уровня лишь у 32,2\% детей и 25,5\% подростков. При этом доля пациентов с выраженной декомпенсацией $\mathrm{HbA}_{1 c}>9 \%$ в группе подростков достигает 45\%. Тем не менее, отмечается значимая положительная динамика показателя в период с 2013 по 2016 гг. с увеличением доли пациентов с целевым контролем $\mathrm{HbA}_{1 c}$. Худшие показатели $\mathrm{HbA}_{1 c}$ у подростков могут быть обусловлены объективной сложностью контроля гликемии в период полового созревания. Полученные данные указывают на приоритетное значение обучения детей и подростков в «Школах для больных СД» и необходимости более тщательного мониторинга гликемии, а следовательно, обеспечения средствами самоконтроля в соответствующем объеме [13].

Положительным моментом можно считать, что, в отличие от взрослых пациентов [5], данный показатель у детей и подростков фиксируется в регистре значительно чаще: у 57\% и 53\% пациентов соответственно; доля пациентов с внесенными данными $\mathrm{HbA}_{1 c}$ в регистр указана на рисунках 11, 12. Контроль $\mathrm{HbA}_{1 с}$ является исследованием, абсолютно необходимым для осуществления мониторинга пациентов с СД, как в клиническом плане для оценки эффективности сахароснижающей терапии и своевременного принятия решения о необходимости ее коррекции, так и организационном - в качестве целевого индикатора качества оказания диабетологической помощи. С этой целью требуется не только повышение качества ввода данных $\mathrm{HbA}_{1 c}$ в регистр (у 100\% пациентов), но и увеличение кратности измерения данного параметра. Принимая во внимание, что у детей - особой когорты риска, - целевые показатели должны быть индивидуализированы во избежание тяжелых гипогликемий [14], этот вопрос становится еще более актуальным.

Частота определения уровня $\mathrm{HbA}_{1 c^{\prime}}$ необходимая для больных СД, определена положением «Алгоритмов специализированной медицинской помощи больным СД» и составляет 1 раз в 3 мес [12].

\section{Анализ распространенности осложнений}

Распределение частоты диабетических осложнений при СД1 и СД2 по данным 81 региона РФ представлено на рис. 13-15.

Таким образом, у детей и подростков с СД из хронических осложнений наиболее часто регистрируется осложнение метаболического характера - диабетическая нейропатия (10,9\% и 40,8\% соответственно при СД1, 4,7\% и 8,8\% при СД2). При СД1 микрососудистые осложнения (ретинопатия и нефропатия) встречаются реже в группе детей, их частота не превышает 2,7\% и 1,4\%; у подростков частота микрососудистых осложнений выше 9,8\% и 8,5\% ретинопатии и нефропатии соответственно (рис. 13). При СД2 микрососудистые осложнения у детей и подростков регистрируются в сопоставимом проценте случаев (рис. 14). Кроме того, при СД2 спектр патологии меняется на более высокую частоту сопутствующих заболеваний, таких как артериальная гипертония (10,4\%), дислипидемия (3,6\%), как следствие метаболического синдрома при СД2 (рис. 15). Частота острых осложнений - диабетической комы (3,2\% против 1,2\%) и кетоацидоза (в 2,5\% против 8\%) в 3-3,4 раза выше в группе подростков, как следствие описанных выше трудностей достижения стабильной гликемии в данный возрастной период [15].

\section{Анализ госпитализаций}

Количество госпитализаций у детей и подростков по данным онлайн-регистра представлено в табл. 5: госпитализировались по данным анамнеза 43,8\% детей и 49,2\% подростков, большинство госпитализаций в 2016 г. (дети 71,9\%, подростки 67,1\%) были по причине СД.

Следует уточнить, что в старом формате регистра не было графы «госпитализация по причине СД», она вве- 
Таблица 6. Клиническая характеристика пациентов в возрасте до 18 лет (дети + подростки) в зависимости от наличия или отсутствия госпитализаций в анамнезе (81 регион РФ по данным онлайн-регистра)

\begin{tabular}{|c|c|c|c|c|c|c|}
\hline \multirow[t]{2}{*}{ Показатель } & \multicolumn{2}{|c|}{$\begin{array}{c}\text { Госпитализации в анамнезе } \\
\text { (по любой причине) }\end{array}$} & \multicolumn{2}{|c|}{$\begin{array}{c}\text { Госпитализации в } 2016 \text { г. } \\
\text { (по любой причине) }\end{array}$} & \multicolumn{2}{|c|}{$\begin{array}{c}\text { Госпитализации в } 2016 \text { г. (по } \\
\text { причине СД) }\end{array}$} \\
\hline & Нет & Да & Нет & Да & Нет & Да \\
\hline Дебют СД, год & 6,7 & 6,8 & 6,5 & $7,0^{*}$ & 6,4 & $7,2 *$ \\
\hline Текущий возраст, лет & 11,2 & $11.9^{*}$ & $12,4^{*}$ & 11,5 & $12,3 *$ & 11,3 \\
\hline Длительность, лет & 4,4 & $5,1 *$ & $6,0^{*}$ & 4,6 & $5,9^{*}$ & 4,1 \\
\hline $\begin{array}{l}\mathrm{HbA}_{1 c^{\prime}} \% \\
\text { (последний визит) }\end{array}$ & 8,5 & $8,8^{*}$ & 8,41 & $9,00^{*}$ & 8,61 & $9,01^{*}$ \\
\hline
\end{tabular}

* - есть достоверное отличие между группами, *отмечена группа с большим показателем $(p<0,05)$.

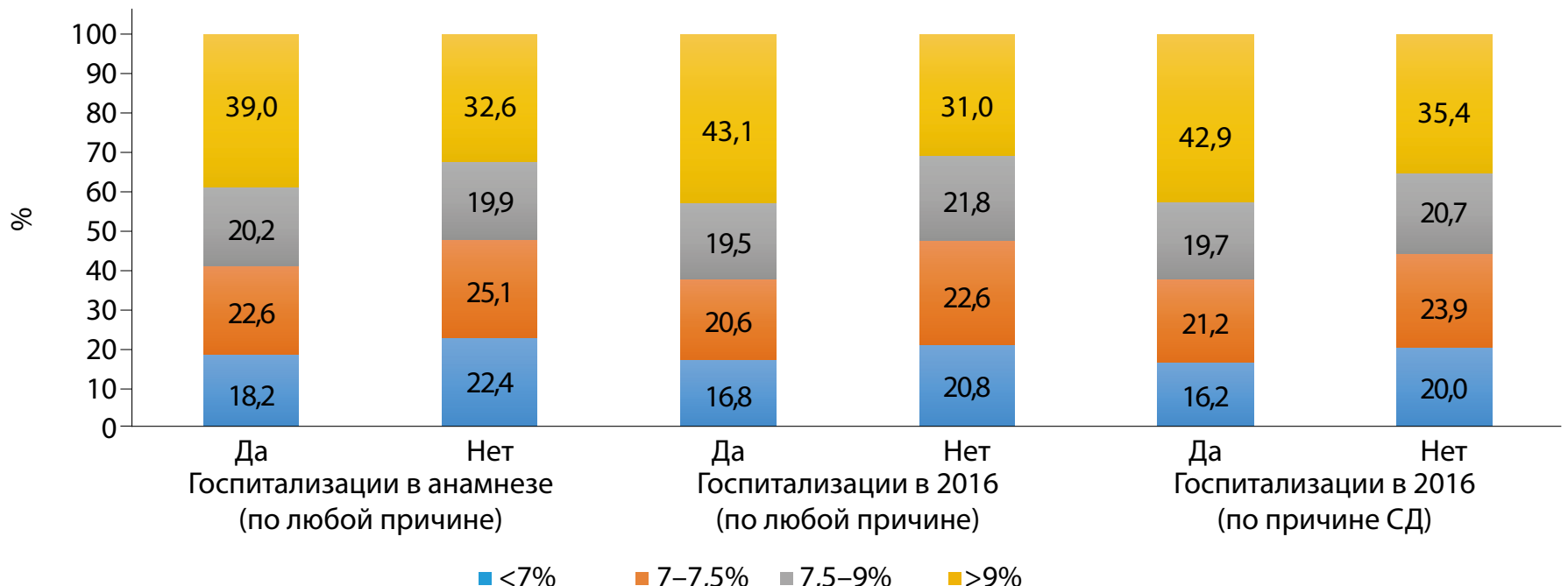

Рис. 16. Распределение пациентов детского и подросткового возраста по уровню НbА в зависимости от наличия и характера госпитализаций (81 регион РФ по данным онлайн-регистра).

Таблица 7. Характеристика терапии у пациентов с СД детского и подросткового возраста (81 регион РФ по данным онлайн-регистра)

\begin{tabular}{|c|c|c|c|c|c|}
\hline & \multirow{2}{*}{$\begin{array}{c}\text { Помповая } \\
\text { инсулиноте- } \\
\text { рапия, абс. (\%) }\end{array}$} & \multicolumn{3}{|c|}{ Базис-болюсная терапия в шприц-ручках, абс. (\%) } & \multirow{2}{*}{$\begin{array}{c}\text { Данные терапии } \\
\text { не указаны, } \\
\text { абс. (\%) }\end{array}$} \\
\hline & & Аналоги & РЧИ и аналоги & РчИ & \\
\hline Дети (0 - <15 лет), n (\%) & $2977(14,6)$ & $14675(72,2)$ & $1216(6,0)$ & $641(3,2)$ & $818(4,0)$ \\
\hline Подростки (15 - <18 лет), n (\%) & $1331(16,1)$ & $6067(73,5)$ & $429(5,2)$ & $108(1,3)$ & $318(3,9)$ \\
\hline Всего, n (\%) & $4308(15,1)$ & $20742(72,6)$ & $1645(5,7)$ & $749(2,6)$ & $1136(4,0)$ \\
\hline
\end{tabular}

Примечание: РчИ - рекомбинантные человеческие инсулины

дена в 2015 г., поэтому данные представлены только за 2016 г.

Анализ клинических характеристик пациентов, которые госпитализировались по сравнению с теми, у которых госпитализаций в анамнезе не было, показал: средний возраст, длительность СД и уровень $\mathrm{HbA}_{1 с}$ были выше в группе с наличием госпитализаций, в том числе в группе «госпитализаций по причине СД» отмечался более высокий уровень $\mathrm{HbA}_{1 с}$ при меньшей длительности и более позднем дебюте заболевания (табл. 6).

Наличие связи госпитализаций с выраженностью декомпенсации СД подтверждается тем, что среди пациентов, которые когда-либо госпитализировались, в том числе по причине СД, доля лиц с уровнем $\mathrm{HbA}_{1 c}>9 \%$ была выше во всех группах по сравнению с пациентами, у которых госпитализаций не было (рис. 16).

Анализ терапии

По данным Федерального регистра СД, большинство пациентов детского и подросткового возраста находят- ся на самых современных видах инсулинотерапии, в том числе помповой терапии (15,1\%) и терапии аналогами инсулина в режиме многократных инъекций $(72,6 \%)$ (табл. 7). Согласно данным компаний-производителей инсулиновых помп, которые были получены на основании информации, предоставленной пользователями и медицинскими работниками, количество детей и подростков на помповой инсулинотерапии может быть значительно выше и достигать в отдельных субъектах РФ 40-50\% пациентов, однако публикаций конкретных цифр по данному вопросу нет. Различия с официальными данными регистра могут быть обусловлены тем, что возможность указания на помповую инсулинотерапию была введена в регистр в 2015 г. и регистрация данных может запаздывать.

\section{выводы}

К концу 2016 г. большинство регионов РФ (81 регион) участвуют в ведении регистра СД в онлайн-формате. 
Данные динамики эпидемиологических характеристик СД в возрастных группах детей и подростков указывают на сохранение стабильного роста распространенности СД1 и СД2. В отношении показателя заболеваемости СД тенденции различны: прослеживается стабилизация и относительное снижение заболеваемости СД1 по сравнению с пиком показателей в 2013-2014 гг. и, напротив, рост заболеваемости СД2. Установлены значительные различия в уровне заболеваемости и распространенности СД между регионами, что может отражать не только географические и этнические особенности, но и качество ведения регистра конкретным субъектом РФ. Отмечается увеличение количества пациентов с достижением целевого уровня $\mathrm{HbA}_{1 c}<7,5 \%$ и уменьшение доли пациентов с выраженной декомпенсацией СД. Частота диабетических осложнений у детей и подростков с СД варьирует, наиболее часто регистрируются осложнения метаболического характера (диабетическая нейропатия). В структуре терапии данной возрастной группы соотношение инсулинотерапии в шприцах-ручках и помповой терапии по данным регистра составляет 80,9\%/15,1\%. Впервые оценены данные количества госпитализаций у детей и подростков. Характеристики госпитализированных пациентов указывают на взаимосвязь госпитализаций с выраженностью декомпенсации СД.

\section{ДОПОЛНИТЕЛЬНАЯ ИНФОРМАЦИЯ}

Финансирование работы. Работа проведена в рамках выполнения Государственного задания Министерства здравоохранения Российской Федерации No AAAA-A16-116011100138-5.

Конфликт интересов. Авторы декларируют отсутствие явных и потенциальных конфликтов интересов, связанных с публикацией настоящей статьи.

Участие авторов. Шестакова М.В., Викулова О.К., Железнякова А.В., Исаков М.А., Лаптев Д.Н., Андрианова Е.А., Ширяева Т.Ю. - анализ и интерпретация результатов исследования, написание текста статьи; Петеркова В.А., Дедов И.И. - финальный анализ результатов и редактирование текста рукописи.

Благодарности. ЗАО «Астон Консалтинг» за техническое сопровождение регистра СД в онлайн-формате.

Всем медицинским специалистам (врачам, медицинским сестрам, регистраторам данных), ведущим активную работу по заполнению базы данных регистра СД.

\section{ПРИЛОЖЕНИЯ [SUPPLEMENTS]}

Приложения доступны на сайте журнала по URL: https://endojournals.ru/index.php/dia/article/view/9460

\section{ПРИЛОЖЕНИЕ 1}

Распространённость сахарного диабета в возрастных группах «ДЕТИ» и "ПОДРОСТКИ" по данным онлайн-регистра в 81 регионе Российской Федерации, 31.12.2016 г.

SUPPLEMENT 1

The prevalence of diabetes mellitus in "CHILDREN" and "ADOLESCENTS" age groups according to the online state diabetes register in 81 regions of the Russian Federation, 31.12.2016.

URL: https://endojournals.ru/index.php/dia/article/downloadSuppFile/9460/2381

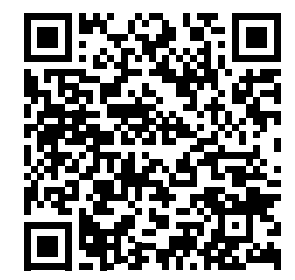

\section{ПРИЛОЖЕНИЕ 2}

Заболеваемость сахарным диабетом в возрастных группах «ДЕТИ» и «ПОДРОСТКИ» по данным онлайн-регистра в 81 регионе Российской Федерации, 31.12.2016 г.

SUPPLEMENT 2

The incidence of diabetes mellitus in "CHILDREN" and "ADOLESCENTS" age groups according to the online state diabetes register in 81 regions of the Russian Federation, 31.12.2016.

URL: https://endojournals.ru/index.php/dia/article/downloadSuppFile/9460/2382

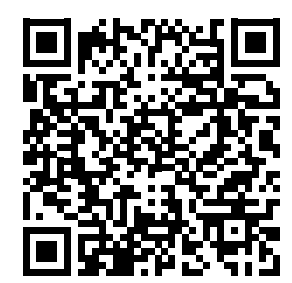

\section{ПРИЛОЖЕНИЕ 3}

Структура причин смерти пациентов с сахарным диабетом по данным онлайн-регистра в 81 регионе Российской Федерации.

SUPPLEMENT 3

The cause-of-death structure for patients with diabetes mellitus according to the online state register in 81 regions of the Russian Federation.

URL: https://endojournals.ru/index.php/dia/article/downloadSuppFile/9460/2383

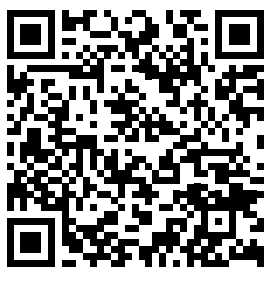

\section{СПИСОК ЛИТЕРАТУРЫ | REFERENCES}

1. Сахарный диабет типа 1: реалии и перспективы. / Под ред. Дедова И.И., Шестаковой М.В. - М.: Издательство медицинское информационное агентство, 2016. [Dedov II, Shestakova MV, editors. Type 1 diabetes mellitus: realities and perspectives. Moscow: Publishing Medical Information Agency; 2016. (In Russ.)]

2. IDF Diabetes Atlas, $8^{\text {th }}$ edition. Brussels: International Diabetes Federation; 2017. Available from: https://www.idf.org/e-library/epidemiology-research/diabetes-atlas/134-idf-diabetes-atlas-8th-edition.html.

3. Щербачева Л.Н., Сунцов Ю.И., Рыжкова С.Г., и др. Мониторинг основных эпидемиологических характеристик сахарного диабета у детей в Москве // Сахарный диабет. - 1999. - Т. 2. - №1. C. 13-17. [Shcherbacheva LN, Suntsov YI, Ryzhkova SG, et al. Monitoring osnovnykh epidemiologicheskikh kharakteristik sakharnogo diabeta u detei v Moskve. Diabetes mellitus. 1999;2(1):13-17. (In Russ.)] doi: 10.14341/2072-0351-5727

4. Дедов И.И., Шестакова М.В., Викулова О.К. Государственный регистр сахарного диабета в Российской Федерации: статус 2014 г. и перспективы развития // Сахарный диабет. - 2015. - Т. 18. №3. - C. 5-22. [Dedov II, Shestakova MV, Vikulova OK. National register of diabetes mellitus in Russian Federation: status on 2014. Diabetes mellitus. 2015;18(3):5-23. (In Russ.)] doi: 10.14341/DM201535-22 
5. Дедов И.И., Шестакова М.В., Викулова О.К. Эпидемиология сахарного диабета в Российской Федерации: клинико- статистический анализ по данным Федерального регистра сахарного диабета // Сахарный диабет. - 2017. - T. 20. - №1. - C.13-41 [Dedov II, Shestakova MV, Vikulova OK. Epidemiology of diabetes mellitus in Russian Federation: clinical and statistical report according to the federal diabetes registry. Diabetes mellitus. 2017;20(1):13-41. (In Russ.)] doi: 10.14341/DM8664

6. gks.ru. [Интернет]. Федеральная служба государственной статистики. [gks.ru. [Internet] Russian Federal State Statistics Service]. Доступно по: www.gks.ru.

7. Ширяева Т.Ю., Андрианова Е.А., Сунцов Ю.И. Динамика основных эпидемиологических показателей сахарного диабета 1 типа у детей и подростков в Российской Федерации (2001-2011 гг.) // Сахарный диабет. - 2013. - Т. 16. - №3. - C. 21-29. [Shiryaeva TY, Andrianova EA, Suntsov YI. Type 1 diabetes mellitus in children and adolescents of Russian Federation: key epidemiology trends. Diabetes mellitus. 2013:16(3):21-29. (In Russ.)] doi: 10.14341/2072-0351-813

8. Дедов И.И., Шестакова М.В., Андреева Е.Н., и др. Сахарный диабет: диагностика, лечение, профилактика. / Под ред. Дедова И.И., Шестаковой М.В. - М.: Издательство медицинское информационное агентство, 2011. [Dedov II, Shestakova MV, Andreeva EN. Diabetes mellitus: diagnostics, treatment, prevention. Dedov II, Shestakova MV, editors. Moscow: Publishing Medical Information Agency; 2011. (In Russ.)]

9. Щербачева Л.Н., Кураева Т.Л., Ширяева Т.Ю., и др. Эпидемиологическая характеристика сахарного диабета типа у детей в Российской Федерации (предварительные данные) // Сахарный duaбem. - 2004. - T. 7. - №3. - C. 2-7. [Shcherbacheva LN, Kuraeva TL, Shiryaeva TY et al. Epidemiologicheskaya kharakteristika sakharnogo diabeta tipa u detei v Rossiiskoi Federatsii (predvaritel'nye dannye). Diabetes mellitus. 2004;7(3):2-7. (In Russ.)] doi: 10.14341/DM200432-7

10. Щербачева Л.Н., Ширяева Т.Ю., Сунцов Ю.И., Кураева Т.Л. Сахарный диабет 1-го типа у детей Российской Федерации: распространенность, заболеваемость, смертность // Проблемы эндокринологии - 2007. - T. 53. - №2. - С. 24-29. [Shcherbacheva LN,
Shiryaeva TY, Suntsov YI, Kuraeva TL. Type 1 diabetes in children: Prevalence, morbidity and mortality in the Russian Federation. Problems of Endocrinology. 2007; 53(2):24-29. (In Russ.)]

11. IDF Diabetes Atlas, $8^{\text {th }}$ edition. Brussels: International Diabetes Feder ation; 2017. Available from: https://www.idf.org/e-library/epidemiology-research/diabetes-atlas/13-diabetes-atlas-seventh-edition.html.

12. Дедов И.И., Шестакова М.В., Майоров А.Ю., и др. Алгоритмы специализированной медицинской помощи больным сахарным диабетом / Под редакцией И.И. Дедова, М.В. Шестаковой, А.Ю. Майорова. - 8-й выпуск // Сахарный диабет. - 2017. - T. 20. - №1S. - C. 1-121. [Dedov II, Shestakova MV, Mayorov AY, et al. Standards of specialized diabetes care. Edited by Dedov II, Shestakova MV, Mayorov AY. 8th edition. Diabetes mellitus. 2017;20(1S):1-121. (In Russ.)] doi: 10.14341/DM8146

13. Дедов И.И., Шестакова М.В., Сунцов Ю.И., и др. Результаты реализации подпрограммы "Сахарный диабет" Федеральной целевой программы "Предупреждение и борьба с социально значимыми заболеваниями 2007-2012 годы" // Сахарный диабет. 2013. - T. 16. - №2S. - C. 1-48. [Dedov II, Shestakova MV, Suntsov YI, Peterkova VA, Galstyan GR, Mayorov AY, et al. Federal targeted programme 'Prevention and Management of Socially Significant Diseases (2007-2012)': results of the 'Diabetes mellitus' sub-programme. Diabetes mellitus. 2013;16(2S):1-48. (In Russ.)] doi: 10.14341/2072-0351-3879

14. Rewers MJ, Pillay K, de Beaufort C, et al. ISPAD Clinical Practice Consensus Guidelines 2014 Compendium. Assessment and monitoring of glycemic control in children and adolescents with diabetes. Pediatric Diabetes. 2014;15(Suppl 20):102-114. doi: 10.1111/pedi.12190

15. Андрианова Е.А., Александрова И.И., Максимова В.П., и др. Оценка степени компенсации углеводного обмена и распространенности диабетических осложнений у детей в возрасте до 14 лет в Российской Федерации // Сахарный диабет. - 2007. - Т. 10. №1. - C. 24-29. [Andrianova EA, Aleksandrova II, Maksimova VP, et al. Otsenka stepeni kompensatsii uglevodnogo obmena i rasprostranennosti diabeticheskikh oslozhnenii u detei v vozraste do 14 let v Rossiiskoi Federatsii. Diabetes mellitus. 2007;10(1):24-29. (In Russ.)] doi: 10.14341/2072-0351-5910

\section{ИНФОРМАЦИЯ ОБ АВТОРАХ [AUTHORS INFO]}

Железнякова Анна Викторовна, к.M.н. [Anna V. Zheleznyakova, MD, PhD], адрес: Россия, 117036, Москва, ул. Дм. Ульянова, д.11 [address: 11 Dm.Ulyanova street, 117036 Moscow, Russia]; ORCID: http://orcid.org/0000-0002-9524-0124; eLibrary SPIN: 81021779; e-mail: azhelez@gmail.com.

Викулова Ольга Константиновна, к.М.Н., доцент [Olga K. Vikulova, MD, PhD, associate professor]; телефон: +7 (499) 124-10-21; eLibrary SPIN: 9790-2665; ORCID: http://orcid.org/0000-0003-0571-8882; e-mail: gos.registr@endocrincentr.ru.

Исаков Михаил Андреевич, к.б.н. [Mikhail A. Isakov]; телефон +7 (903)5185767 ORCID: orcid.org/0000-0001-9760-1117, eLibrary SPIN: 5870-8933, e-mail: m.isakov@aston-health.com.

Лаптев Дмитрий Никитич, К.М.H. [Dmitry N. Laptev, MD, PhD]; телефон: +74956682079 (доб. 5310);

ORCID: http://orcid.org/0000-0002-4316-8546; eLibrary SPIN: 2419-4019; e-mail: laptevdn@ya.ru.

Андрианова Екатерина Андреевна, к.M.H., В.H.c. [Ekaterina A. Andrianova, MD, PhD, leading research associate]; ORCID: http://orcid.org/0000-0002-6611-8170; eLibrary SPIN: 7496-4580; e-mail: katandr13@list.ru.

Ширяева Татьяна Юрьевна, K.M.н. [Tatyana Y. Shiryaeva, MD, PhD]; ORCID: http://orcid.org/0000-0002-2604-1703; eLibrary SPIN: 1322-0042; e-mail: tasha-home@list.ru.

Петеркова Валентина Александровна, д.м.н., профессор, академик PAH [Valentina A. Peterkova, MD, PhD, Professor]; ORCID: http://orcid.org/0000-0002-5507-4627; e-mail: peterkova-va@hotmail.com.

Шестакова Марина Владимировна, д.м.н., профессор, академик PAH [Marina V. Shestakova, MD, PhD, Professor]; ORCID: http://orcid.org/0000-0003-3893-9972; eLibrary SPIN: 7584-7015; e-mail: nephro@endocrincentr.ru.

Дедов Иван Иванович, д.м.н., профессор, академик РАH [Ivan I. Dedov, MD, PhD, Professor];

ORCID: http://orcid.org/0000-0002-8175-7886; eLibrary SPIN: 5873-2280; e-mail: dedov@endocrincentr.ru.

\section{ЦИТИРОВАТЬ:}

Дедов И.И., Шестакова М.В., Петеркова В.А., Викулова О.К., Железнякова А.В., Исаков М.А., Лаптев Д.Н., Андрианова Е.А., Ширяева Т.Ю. Сахарный диабету детей и подростков по данным Федерального регистра Российской Федерации:динамика основных эпидемиологических характеристик за 2013-2016гг // Сахарный диабет. - 2017. - T. 20. — №6. - C. 392-402.doi: 10.14341/DM9460

\section{TO CITE THIS ARTICLE:}

Dedov II, Shestakova MV, Peterkova VA, Vikulova OK, Zheleznyakova AV, Isakov MA, Laptev DN, Andrianova EA, Shiryaeva TY. Diabetes mellitus in children and adolescents according to the Federal diabetes registry in the Russian Federation: dynamics of major epidemiological characteristics for 2013-2016. Diabetes mellitus. 2017;20(6):392-402. doi: 10.14341/DM9460 